\title{
A CONQUISTA DE A CINZA DAS HORAS, DE MANUEL BANDEIRA
}

\author{
Ésio Macedo Ribeiro
}

Todo bibliófilo, após elencar o que deverá integrar sua biblioteca, começa a mais árdua das aventuras: conseguir toda a obra de autor que admira. No meu caso, que disponho de uma biblioteca abarcando os escritores mais significativos do movimento modernista de 1922, passando pelas vanguardas, como o Concretismo, até os dias atuais, a tarefa é duplamente árdua.

Primeiro porque os autores brasileiros mais conhecidos, como Carlos Drummond de Andrade, Murilo Mendes, Cecília Meireles, Rachel de Queiroz, bancaram as edições de seus primeiros livros e tiveram outros publicados em pequenas tiragens. Segundo porque normalmente o bom colecionador é exigente e quer encontrar um exemplar em perfeito estado de conservação. No caso brasileiro, isso é muito complicado, pelo fator climático do país e ainda pelo fato de que, até os anos 1980, boa parte dos bibliófilos, ao encadernarem os livros, retiravam as capas e contracapas e até mesmo aparavam a obra, o que hoje na bibliofilia é considerado crime de lesa literatura! Outro fator é a data da edição do livro: quanto mais antigo, menos possibilidade de obtê-lo. 
No que se refere a A Cinza das Horas, de Manuel Bandeira (18861968), tudo isto é pertinente. Foi lançado às próprias custas do poeta, em papel de baixa qualidade e em tiragem pequena há exatos 103 anos - o livro é de 1917. Nunca vi esse livro em nenhuma das bibliotecas que frequentei, públicas ou privadas.

É um grande desafio colecionar a obra de Manuel Bandeira, por ele ter feito algumas das edições mais difíceis de serem encontradas hoje. Para ficar num só exemplo, citemos o raríssimo Estrela da Manhã, cuja tiragem foi de apenas 47 exemplares. Volume que, infelizmente, minha biblioteca ainda não possui. Digo isso porque nenhum colecionador deixa de acreditar que o fruto do seu desejo possa um dia ser alcançado.

A Cinza das Horas, seu primeiro livro, cujos poemas foram escritos na juventude do poeta, ainda vinculados às escolas simbolista e parnasiana, revela um Bandeira já dono de linguagem própria, expressando as agruras da condição humana, em versos que exprimem as dores do amor e da morte, do desamparo e da solidão.

Este livro era, desde sempre, um dos mais procurados por mim. Felizmente a persistência às vezes vence o tempo, nos levando à conquista do objeto do desejo, seja ele qual for. Em certo dia de 1996 recebi um telefonema de conhecido livreiro de São Paulo. Disse-me que havia adquirido uma biblioteca, cujos livros poderiam me interessar e que eu passasse por sua loja para vê-los. Pedi para ele adiantar alguns títulos para eu saber se valeria a pena a visita (ele nunca prestava muita atenção ao que eu colecionava). Nada respondeu, despediu-se e desligou.

No dia seguinte, bem cedo, fui encontrá-lo. Tratava-se de um lote bastante interessante. Muitos títulos do Modernismo, que eu não tinha e que me interessavam. Mas, como eu sabia que ele tinha o péssimo hábito de não pôr os preços nos livros e dar o preço conforme a cara do freguês, ainda assim fui separando vários para, ao final, escolher os que minhas finanças permitiriam comprar. Ele, então, se dirigiu a um armário próximo, retirou um pequeno volume e o pôs em minhas mãos. Eu não demonstrei o quão tonto tinha ficado. Com mãos geladas toquei pela primeira vez naquela joia.

Não conseguia acreditar: A Cinza das Horas estava em minhas mãos. Respirei fundo e não fiz cara de surpresa. Como quem não quer nada perguntei o preço. Ele respondeu com um indefectível risinho sacana: sete mil reais. Eu, exausto, me sentei. Comprei o que pude, me despedi e rumei para casa. A frustração não me deixou dormir naquela noite.

O tempo passou, cheguei a pensar nunca mais ver aquele livro. Mas continuei procurando, pesquisando nos sítios da internet de livreiros tanto do Brasil quanto do exterior, sem nunca desistir. Até que num belo dia - e era! - recebi ligação de um amigo, também bibliófilo, dizendo 
MANUEL BANDEIRA

\section{A CINZA DAS HORAS.}

MANUEL BANDEIRA

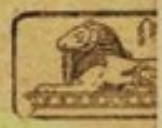

8

A CINZA DAS RIORAS.

A tritan tro dalotis

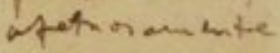

40 Des JAX:

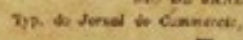

Manmel Dankir

19:

R: 195\%

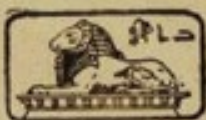

EIO DE JAxEmo

Typ. es Jirnat do Comineresis, de Rodricues a $\mathrm{C}$.

1017

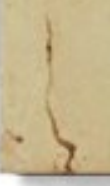

Capa e página de rosto da primeira

edição de A Cinza das Novas, de Manuel

Bandeira. Coleção Ésio Macedo Ribeiro. 
que naquela noite aconteceria um leilão de arte em São Paulo e que, entre as pinturas e esculturas do catálogo, também havia alguns lotes de livros, valeria eu dar uma olhada.

Como sempre fizemos, eu e este amigo, depois de lermos o catálogo, trocávamos informações sobre os lotes que queríamos dar lances, para que não inflacionássemos os valores de um para o outro. Feito isto, combinávamos que se houvesse algum lote que interessasse a ambos, estipularíamos o valor máximo que cada um lançaria. Assim, se o valor ultrapassasse o estipulado, o que desejasse lançar mais, se conseguisse, poderia ficar com o lote.

Ao folhear o caprichado catálogo, me deparei com a foto de um muito bem conservado exemplar de A Cinza das Horas, com a seguinte referência: "Manuel Bandeira, A Cinza das Horas, $1^{\text {a }}$ edição, com dedicatória. Rio de Janeiro. Typ. do Jornal do Commercio, de Rodrigues \& C. 1917. 17x12 cm. Exemplar em ótimo estado de conservação". O livreiro foi correto, não mencionou "impecável” pelo fato de o livro ter tido a lombada restaurada. Mas estava na brochura original, conservando as capas e com a seguinte dedicatória: "A José Fausto da Costa, / afetuosamente / Manuel Bandeira / Rio 1917”.

Depois de marcar os lotes em que eu almejava dar lances, telefonei para meu amigo. Falei que queria muito aquele lote. Mas não podia desrespeitá-lo, pelo fato de ele ter sido, como sempre, muito correto para comigo. "Irei até $\mathrm{x}$ ", disse-me ele. Isso me deixou surpreso, não era grande o valor máximo que ele iria oferecer. Penso, hoje, que ele não tinha noção de quanto o livro realmente valesse. Respondi: “Ok, se os lances passarem do seu x começarei a lançar”. Cheguei a pensar que o livro pudesse alcançar uma cifra absurda, dada a sua raridade. E eu que o procurava a vida inteira estava preparado e disposto a dar até duas vezes acima do valor acordado.

Vi quando meu amigo começou a dar seus lances. Esperei. Rapidamente alguém cobriu o $\mathrm{X}$ dele. Imediatamente dei meu primeiro lance. E foram somente mais dois. O derradeiro, o meu. Mal podia crer que tinha arrematado esse tão almejado item para a minha coleção.

No dia seguinte corri para o endereço do leiloeiro para pagar e retirar o que eu arrematara. Conferi os livros com todo cuidado, mas sem demonstrar nada que deixasse transparecer que o Bandeira que eu adquirira era extremamente raro.

Voltei para casa com o pacote, pus sobre a mesa e liguei imediatamente para meu amigo para agradecer. Ele disse ter ficado feliz pela minha conquista. Falei sobre o que tinha acontecido para que eu conseguisse o livro por valor relativamente baixo - quase a metade a menos do que o do primeiro exemplar que tive nas mãos. Acho 
que poucas pessoas tiveram acesso ao catálogo daquele leilão. E que poderiam supor que não havia livros, porque o catálogo não trazia imagens deles na capa.

Colecionador é como pescador, que sempre quer contar do peixe conquistado com dificuldade, do maior, do mais bonito. Mas, diferentemente das histórias de pescador, quase nunca aumenta o ponto. Hoje, para minha alegria, este A Cinza das Horas faz parte da minha bandeiriana.

Como esta, tenho mais centenas de histórias sobre a formação da minha biblioteca. Na próxima oportunidade, gostaria de contar que eu consegui Estrela da Manhã. Torçam por mim e me auxiliem, se possível.

\section{SOBRE 0 AUTOR}

Ésio Macedo Ribeiro é doutor em Literatura Brasileira pela USP, escritor e bibliófilo. Publicou dezesseis livros. Atualmente trabalha em seu segundo romance, que tem o título provisório de 88 ou $\mathrm{O}$ Vale das Coisas Perdidas. 


\section{A CONQUISTA DE A CINZA DAS HORAS, DE MANUEL BANDEIRA $p .82$}

RESUMO Por conta da tiragem reduzida nos anos de publicação, Manuel Bandeira é um dos autores com as primeiras edições mais difíceis de serem encontradas e colecionadas. Esse texto é um relato pessoal da conquista, após algumas tentativas frustradas, de um dos raríssimos exemplares em primeira edição de A Cinza das Horas (1917).

BIBLIOFILIA - MANUEL BANDEIRA • A CINZA DAS HORAS - LETRAS PRIMEIRAS EDIÇÕES.

\author{
THE CONQUEST OF A CINZA DAS \\ HORAS (THE GRAY OF THE HOURS), \\ BY MANUEL BANDEIRA \\ ABSTRACT Because of the reduced \\ circulation in the years his books were \\ published, Manuel Bandeira is one \\ of the authors with the hardest first \\ editions to be found and collected. \\ This text is a personal narrative of the \\ conquest, after some unsuccessful \\ attempts, of one of the very rare copies \\ of 1917's A Cinza das Horas. \\ BIBLIOPHILIA • MANUEL BANDEIRA \\ - A CINZA DAS HORAS • \\ FIRST EDITIONS
}

